\title{
O Espelho da História: práticas patrimonialistas e transformações na paisagem urbana de Viçosa (1980-2010)
}

The Mirror of History: patrimonialism practices and transformations of the urban landscape of Viçosa (1980-2010)

\author{
Leonardo Civale \\ Walkíria Maria Freitas Martins ${ }^{* *}$
}

\begin{abstract}
Resumo
Ao final do século XX e início do século XXI, as paisagens urbanas modificadas, após anos de atividades industriais, vêm passando por um processo de reconfiguração. As ações nos centros urbanos foram projetadas pelos interesses do capital ou por decisões de políticas públicas. Os grupos dominantes optam por reconstruir as paisagens urbanas ditas degradas, levando em consideração os interesses do capital e o narcisismo de memórias coletivas previamente selecionadas. Portanto, a construção, reconstrução ou preservação de paisagens urbanas é, na realidade, um campo aberto, de conflito acirrado, de discussão apaixonada e veleidades estéticas entre os diferentes grupos que habitam o mesmo espaço. Tal fato reforça a importância do estudo da dimensão simbólica nas paisagens urbanas. Este trabalho analisa as políticas patrimoniais do município de Viçosa, entre os anos de 1980 e 2010 e tem o objetivo de interpretar as discussões e os discursos relacionados ao patrimônio, que modelaram a paisagem da cidade.
\end{abstract}

Palavras-chave: Paisagem Urbana; Memória; Identidade; Patrimônio; Cidadania.

\begin{abstract}
At the end of the twentieth century and the beginning of the twenty-first century, the modified urban landscapes, after years of industrial activities, have been passing through a reconfiguration process. The actions in the urban centers have been projected by the interests of the capital or by public policy decisions. The dominant groups choose to rebuild the urban landscapes degraded said taking into account the interests of capital and the narcissism of collective memories previously selected. Therefore, the construction, reconstruction or preservation of urban landscapes is, in reality, an open field of conflict raging, passionate discussion and aesthetic attempts between the different groups that inhabit the same space. This fact reinforces the importance of the symbolic dimension study of urban landscapes. This work interprets the patrimonialism policies of Viçosa municipality, between 1980 and 2010 and aims to interpret the discussions and speeches, related to the patrimony, that modeled the urban landscape.
\end{abstract}

Keywords: Urban Landscape; Memory; Identity; Heritage; Citizenship.

\footnotetext{
* Doutor em História do Pensamento Geográfico pela Universidade Federal do Rio de Janeiro (UFRJ). Professor do Programa de Pós-graduação em Patrimônio Cultural, Paisagens e Cidadania da Universidade Federal de Viçosa (UFV).

** Doutoranda em História pela Universidade Federal do Estado do Rio de Janeiro (Unirio).
} 


\section{Introdução}

Paris muda! Mas nada em minha nostalgia Mudou! Novos palácios, andaimes, lajedos, Velhos subúrbios, tudo em mim é alegoria, E essas lembranças pesam mais do que os rochedos. (BAUDELAIRE, 2012, p. 450-451).

As paisagens urbanas recentes são o resultado das diferentes respostas culturais locais à escala planetária da economia, pois vão sofrer transformações radicais com o processo de globalização ainda em curso. São essas paisagens, resultado, não de uma cultura homogênea, mas, sobretudo, de um dramático conflito de classes no interior de cada cultura local que, por hora, se mostram um interessante objeto de estudo (COSGROVE, 2004). Novas abordagens permitem perceber que as paisagens geográficas e, sobretudo, as paisagens urbanas estão passando por um violento processo de transformação. Ruas, bairros, regiões portuárias e, porque não dizer, cidades inteiras adquirem novas funções e passam por um processo de ressignificação.

Desde a reunião da Conferência Geral da Organização das Nações Unidas para a Educação, Ciência e Cultura, realizada em Paris, entre os dias 17 de outubro e 21 de novembro de 1972, temos assistido a um crescente movimento de abrangência mundial, seja no sentido da preservação do patrimônio material e imaterial, seja no que diz respeito ao patrimônio natural. Portanto, a aprovação da Convenção para a Proteção do Patrimônio Mundial Cultural e Natural, por ocasião da reunião, continua ecoando até os dias atuais. Desde então, tem havido um importante movimento, de parte de governos, instituições, entidades não governamentais, empresários ligados ao setor de turismo e parcelas das populações locais, reivindicando o título de patrimônio histórico ou natural da humanidade para os mais diversos lugares do planeta. Atualmente, no Brasil, junto a antigos centros urbanos listados como patrimônios históricos, existem também locais que são inscritos como patrimônio natural da humanidade. Além disso, a cidade do Rio de Janeiro, recentemente, obteve o título de patrimônio mundial, na categoria de paisagem cultural.

Neste artigo iremos nos concentrar em três perspectivas de análise do papel das políticas públicas sobre o patrimônio na construção de cenários urbanos. A primeira seria o questionamento das políticas públicas, seu alcance, suas consequências, seus critérios e o uso que fazem da memória social na definição dos bens materiais ou imateriais. Em outras palavras, nessa perspectiva, o objeto de estudo seria a crítica dos 
critérios de classificação de bens históricos e naturais. No cenário atual, ainda que, a incorporação da ideia de patrimônio imaterial e de patrimônio natural tenha ampliado a abrangência das políticas de patrimônio, o tombamento de bens históricos, que representam a memória de um grupo da população, vem provocando a reação ou a indiferença de outras parcelas da população. Esses segmentos sociais alegam a desqualificação ou invisibilização de sua memória social. Considerando a segunda perspectiva, o artigo aponta para a necessidade de se investigar o papel de intelectuais específicos, a ação dos homens públicos e os interesses particulares dentro das diferentes instituições encarregadas de elaborar as políticas públicas sobre a preservação do patrimônio, espalhadas por uma miríade de cidades no país. O terceiro movimento questiona como as políticas públicas interferiram, diretamente ou indiretamente, na construção de cenários urbanos e paisagens culturais contemporâneos. Na esteira dessas discussões, o artigo debruça-se sobre o conceito de paisagem, caro à geografia, visando refletir sobre as transformações dos cenários urbanos. As políticas públicas sobre o patrimônio ou cristalizam um determinado cenário urbano, como uma espécie vestígio do passado, ou dialogam com os diferentes interesses do presente e propiciam um cenário completamente ressignificado.

São essas questões e desafios que a seguir procuraremos refletir, mas que também poderiam servir de norte a orientar os estudos sobre as ilações entre as políticas públicas sobre o patrimônio histórico e natural, a produção da memória social e a construção de novos cenários urbanos.

\section{Paisagem urbana como história}

Nas duas últimas décadas do século XX e início do século XXI, já se tem condição de debruçar-se sobre os impactos do processo de globalização espalhados pelos diferentes centros urbanos do planeta (HARVEY, 1992). As paisagens urbanas que se encontravam degradadas, após anos de atividades industriais e comerciais, passaram por um amplo processo de reconfiguração. Os cenários em ruínas dos antigos centros urbanos, fruto do esgotamento do processo de acumulação primitiva, foram alvo dos interesses do capital, das instituições governamentais, dos grupos sociais organizados. Os interesses do capital se manifestam geralmente de duas maneiras: fazer tábula rasa das zonas de obsolescência ou ressignificar essas áreas, criando locais direcionados à cultura, ao turismo e à diversão. No que diz respeito às instituições 
governamentais, desejosas de reverter o processo de obsolescência e degradação urbana, agem em torno da preservação. Já os grupos organizados, estes primam pela preservação daquilo que represente memória coletiva, ainda que para isso seja preciso reativar a memória de um grupo ou mesmo inventá-la.

As paisagens urbanas, classificadas ou não como patrimônio histórico e cultural, são o resultado de uma ação intencional, direcionada e orquestrada no espaço urbano por interesses distintos. Sendo essa ação projetada pela sociedade civil organizada, por instituições governamentais ou pelos interesses do capital, apenas reforça a importância da dimensão simbólica na construção das paisagens. Os grupos dominantes optam por reconstruir as paisagens urbanas ditas degradas, levando em consideração os interesses do capital e o narcisismo de memórias coletivas, previamente selecionadas. Portanto, a construção, a reconstrução ou a preservação de paisagens urbanas é, na realidade, um campo aberto de conflito acirrado, de discussão apaixonada e de veleidades estéticas entre os diferentes grupos que habitam o mesmo espaço.

Não há como negar, contudo, dado o caráter histórico da produção das paisagens urbanas, sobretudo, os interesses intrínsecos da economia de mercado. Todavia, seria virar as costas para o óbvio, não reconhecer a necessidade dessa mesma economia de mercado, de agregar valor simbólico e consumo distintivo às mercadorias dispostas no espaço urbano. No horizonte da modernidade do início do século XXI, as paisagens urbanas, ainda que sejam realidades concretas, são também realidades discursivas e mercadológicas. Não há como esquecer que a paisagem urbana é resultado de decisões de bases racionais e econômicas, mas também é fruto de decisões políticas e simbólicas, sendo, portanto, culturalmente orientadas. Assim, a paisagem urbana que foi construída e permanece preservada, pode ser observada, lida ou interpretada como um texto escrito por mãos humanas. Nesse sentido, deve ser analisada como uma das possibilidades, àquela que os interesses supracitados desenharam no espaço, dentre outras tantas possíveis.

A paisagem urbana se constrói de maneira incontornável enquanto história, na medida em que é produzida por intencionalidades humanas, portanto, ainda que, por ventura, tal ou qual paisagem, possa conter aspectos puramente naturais, a paisagem é inescapavelmente cultural, e transitória, uma vez que é o resultado das intrincadas negociações entre os atores que habitam as cidades. Dito de outro modo, a paisagem urbana é o maior artefato cultural produzido pelas sociedades humanas e, portanto, como qualquer artefato humano, mesmo sendo o resultado de interesses conflitantes e 
comumente representar os desejos das classes mais favorecidas, também reflete as experiências estéticas dessas sociedades.

Não há como negar que vivemos em uma contemporaneidade marcada pela velocidade, velocidade na produção de mercadorias, no transporte e no consumo, na redução de distâncias, de construção de imagens e de produção e circulação da informação. A constatação desse fato deveria produzir uma sensação de aceleração do tempo, uma fuga constante do presente, no entanto, ante a perspectiva de uma crise ambiental sem precedentes, a sensação que impera é a de ausência de futuro. A resposta cultural à falta de perspectiva de futuro tem sido a incorporação do passado. O presente se expande e, em uma estratégia discursiva, incorpora o passado (GUMBRECHT, 2015). A velocidade da produção e do consumo, característicos da modernidade do final do século XX, gerou uma enorme sensação de perda e vazio. Do ponto de vista cultural, o vácuo produzido pelo ritmo acelerado do tempo foi preenchido com a noção de pertencimento e, consequentemente, o desejo de identidade.

Diante dos obstáculos de se pensar um futuro cuja utopia da felicidade geral era possível, volta-se ao passado. Não ao passado histórico, que chegaria à luz do presente como fruto do trabalho dos historiadores, mas ao passado idealizado e romantizado pela memória social de uma coletividade atônita ante as transformações presentes. Esse fenômeno cultural provocou a busca contemporânea por aquilo que seria uma identidade local e, consequentemente, atiçou as brasas da memória coletiva.

Desse modo, o período histórico que engloba as últimas décadas do século XX e as duas primeiras do século XXI, trouxe à tona os discursos sobre a memória, o interesse pelas paisagens urbanas e a luta pelo patrimônio cultural. Porém, uma vez que a memória coletiva é um território de conflitos e estes podem ser concretizados naquilo que se preserva ou, apagado, naquilo que se destrói, o movimento de grupos sociais na luta pela construção de uma memória social acirrou a luta pelas paisagens urbanas.

Desde a aurora da modernidade, nas diferentes cidades brasileiras, o que foi preservado é a memória social das classes mais favorecidas, cristalizada pelos diferentes processos de tombamento oficial. Não seria, portanto, obra do acaso, que os bens tombados sejam, majoritariamente, aqueles que respondem a uma estética moderna e, o seu contraponto, os bens que resguardam um passado colonial luso brasileiro. O que foi preservado, portanto, é o enquadramento de uma memória da sociedade colonial, bem como, os esforços da nação de se ver livre desse passado colonial. Em outras palavras, a ação oficial preservou, por um lado, o resultado das diferentes etapas de modernização 
republicana, os distintos esforços de superação do atraso e, por outro, o passado colonial barroco.

No que diz respeito à preservação do patrimônio histórico e cultural, seja o passado colonial, seja e as diferentes experiências modernas, algumas cidades são privilegiadas em detrimento de outras. Todavia, hoje em dia, ante o crescimento exponencial e mercadológico da atividade turística, uma miríade de cidades brasileiras não importando seu valor, visibilidade ou tamanho, se volta para a preservação de locais, logradouros, ruas ou até mesmo bairros inteiros. A luta pela preservação do passado através de recordações coletivas, parece ter se transformado em um combate que vem sendo travado no seio das cidades contemporâneas. Seus protagonistas, frequentemente, assumem o papel de guardiões da memória, do saber e da identidade e mergulham no passado retórico a sustentar suas posições no presente.

Essa força historicista tem desejado e orientado a preservação, conservação e transmissão do patrimônio cultural comum, de cunho material ou imaterial, de nações, sociedades ou grupos de pressão. Evidentemente, tal constatação não tem a intenção de negar o valor dos bens históricos e culturais como herança, mas considerar que a preservação dos mesmos está atrelada às noções de memória, pertencimento e identidade construídas por mediadores intelectuais, imbuídos do papel de porta-vozes da consciência social.

Desse modo, podemos identificar pela ação política de mediadores sociais, mas, sobretudo, pela ação dos órgãos oficiais, uma espécie de obsessão memorialista, cujo objetivo consciente ou não, é a preservação da memória e identidade da comunidade ou da nação. Entretanto, seria muita ingenuidade acreditar que os diferentes grupos que compõem uma sociedade tenham a mesma capacidade de imprimir no espaço seus quadros de memória e, consequentemente, suas identidades. Normalmente, os órgãos oficiais e os intelectuais orgânicos tendem a organizar a memória de acordo com os interesses de grupos hegemônicos.

De modo curioso ou compensatório a modernidade teve o condão de abarcar a totalidade do tempo. Até mesmo aqueles que antes olhavam para o futuro, hoje não se cansam de tentar construir e reconstruir o passado. Nesse sentido, o papel exercido pela memória é fundamental no mundo contemporâneo, pois ela pode ser construída e reconstruída de acordo com as circunstâncias históricas e os interesses específicos, já que o passado não passa de um processo em construção permanente. Portanto, o desaparecimento ou a permanência de determinados objetos e práticas no espaço 
respondem, intrinsecamente, salvo raras exceções, a projetos oficiais ou de interesses específicos de preservação e conservação de uma determinada memória.

\section{A paisagem urbana, a memória e o patrimônio cultural}

No Brasil, historicamente, as políticas de preservação de bens históricos e culturais são elaboradas, desde os anos 30 do século passado, por um órgão criado especialmente para esse fim, o Serviço de Patrimônio Histórico e Artístico Nacional. Criado em 1937, no Governo de Getúlio Vargas e, dirigido durante 30 anos por Rodrigo Melo Franco de Andrade, o atual IPHAN, contou com a colaboração dos mais brilhantes intelectuais do país em sua época. Entre seus colaboradores estão nomes como, Mario de Andrade, Carlos Drummond de Andrade, Manuel Bandeira, Lucio Costa, Aluísio de Magalhães e outros.

O papel exercido por essa instituição e a visibilidade alcançada, podem ser atestados, pela dimensão intelectual dessas ilustres figuras que fizeram parte de suas fileiras. As políticas públicas que deliberavam sobre a preservação e conservação dos bens históricos e culturais definiram, desde então, os ícones espalhados por todo o país que deveriam ser catalogados. Portanto, desde a primeira metade do século $\mathrm{XX}$, o patrimônio histórico e cultural, ancorado não apenas em uma sólida historiografia oficial, mas também em rígidos valores estéticos, espelhava uma concepção de nação e atuava diretamente na preservação de paisagens urbanas. Por um lado, o patrimônio histórico e cultural refletia a história oficial da nação e, por outro, uma determinada concepção de identidade nacional. A atuação do Serviço de Patrimônio Artístico Nacional incidia, ainda que não exclusivamente, sobre as paisagens urbanas. Não por acaso, o projeto de preservação do patrimônio histórico nacional, bem como, a instituição responsável por elaborar a política de preservação foram gestados no seio de um ambicioso projeto de Estado Nacional. O Estado Nacional construído a partir da Revolução de 30, incorporava duas dimensões políticas que se completavam. Procurando um lugar no futuro, o Estado de Vargas apostava em políticas desenvolvimentistas e modernizadoras. Entre essas, figurava a remodelação, via planejamento urbano, das grandes cidades do país, bem como, a adequação das cidades, sobretudo o Rio de Janeiro, às exigências da modernidade. A outra dimensão, de cunho simbólico, mas não menos importante, seria um investimento intelectual na memória social, no sentido de se construir um passado nacional, em outras palavras, uma 
identidade nacional que desse uma face ao país. As políticas públicas sobre o patrimônio estavam, portanto, incluídas nesse projeto.

Nos anos 70 do século XX, o Serviço de Patrimônio Histórico e Artístico Nacional se transformaria em IPHAN e, sob a direção de Aloísio de Magalhães, o instituto se orientaria por outros critérios, muito mais amplos que os anteriores. $\mathrm{O}$ IPHAN se livraria do binômio nacional e popular que, tradicionalmente, orientava a política de bens históricos e culturais e, ainda que de forma um pouco tímida, ampliaria os critérios que balizavam o patrimônio nacional. Nesse momento entrariam em cena as noções de patrimônio imaterial que incluiria a multiplicidade de formações culturais que se estendiam por todo o território nacional.

Uma simples análise das políticas públicas de preservação e conservação sobre o patrimônio histórico revelaria, claramente, o alcance e as consequências sociais dessas políticas. Essas iniciativas de preservação e conservação de bens históricos e culturais tiveram o mérito, reconhecido a posteriori, de preservar, núcleos urbanos pretéritos de cidades, sítios históricos e mesmo paisagens naturais tidas como reminiscências.

Entretanto, ante a complexidade da contemporaneidade e, com as vantagens da retrospecção, as próprias políticas sobre a preservação do patrimônio histórico material e imaterial, bem como aquelas relativas ao patrimônio natural no país, serviriam como objeto de estudo. Atualmente, essas políticas, longe de se circunscreverem apenas aos problemas relativos ao patrimônio, têm o condão de iluminar questões essenciais, que envolvem a sociedade como um todo. Problemas estes que relacionam intrinsecamente a questão do patrimônio histórico e natural, com a construção de uma memória social, com lutas por representação e identidade e, até mesmo, com inúmeras disputas territoriais entre grupos subalternizados e interesses particulares.

Tendo em vista essas considerações sobre dimensão simbólica da paisagem urbana, apresentaremos a seguir, algumas reflexões acerca das transformações sofridas pela paisagem urbana do município de Viçosa, localizado na microrregião da Zona da Mata, no Estado de Minas Gerais.

Como em tantas outras cidades do Brasil e do mundo, a cidade de Viçosa vem passando, desde a década de 1970, por um acelerado processo de transformações em sua paisagem urbana. Nesse caso específico, um elemento que pode ser considerado como 
grande responsável por tais mudanças, foi a federalização da antiga Universidade Rural do Estado de MG (UREMG), transformada em Universidade Federal de Viçosa (UFV), no final da década de 1960 .

A chegada de considerável contingente populacional vindo de outras localidades colaborou para o desencadeamento de rápidas mudanças na cultura local e também no tecido urbano. A área central da cidade, mais próxima à UFV, passou a ser alvo do setor imobiliário, ávido por atender à grande demanda por moradias naquela região. Coincidentemente, essa área central de Viçosa é também enaltecida pelos principais memorialistas locais, como a principal região que remonta às origens da cidade. Além disso, o Centro de Viçosa também estaria relacionado ao momento histórico, considerado por aqueles memorialistas, como um dos mais importantes da cidade: a carreira política de Arthur da Silva Bernardes, desde sua atuação como vereador e Presidente da Câmara Municipal de Viçosa, passando pela presidência do Estado de Minas Gerais, até a sua chegada ao cargo de Presidente da República, entre os anos de 1906 e 1924; a chegada da linha férrea, a construção das estações ferroviárias e do balaústre; a construção da Escola Superior de Agricultura e Veterinária (ESAV) - futura UFV - e do antigo Patronato Agrícola - atual CENTEV. Tais eventos - marcariam aquele período vivenciado pela cidade de Viçosa.

As transformações aceleradas sofridas pela cidade a partir dos anos 1970 seriam alvo de análises, a partir da década seguinte, por memorialistas, políticos, jornalistas, entre outros moradores de Viçosa. Em geral, percebe-se a atuação de determinados grupos sociais no sentido de definir uma identidade local em oposição ao que seria por eles, entendido como uma "presença forasteira". Tal discurso, somado às preocupações com a preservação da memória e com o desenvolvimento de atividades culturais, visando à indústria do turismo, provocaria uma acalorada discussão na cidade, a partir da década de 1990. Deve-se ainda considerar que a criação da Lei "Robin Hood" (Lei do ICMS Cultural, que faz repasses aos municípios em relação aos seus investimentos na área cultural) pelo Estado de Minas Gerais, em meados dos anos 90, também foi um elemento importante naquele contexto.

Todos esses fatores contribuíram para o estabelecimento de um cenário no qual preservação da memória e da identidade e, consequentemente, do patrimônio históricocultural e natural de Viçosa seriam amplamente discutidos. No final da década de 1990, seria criado o Conselho Municipal de Cultura, Patrimônio Cultural e Ambiental de Viçosa (CMCPCAV) e teria início outro processo de intervenção na paisagem urbana de 
Viçosa, desta vez, sob influência direta de políticas públicas de preservação do patrimônio.

Se considerarmos a diversidade de grupos sociais que compõem uma cidade e a luta cotidiana desses mesmos grupos pelos espaços públicos da cidade, torna-se evidente a constatação de que o processo de proteção ao patrimônio é uma luta pela memória. Nesse sentido, são explicitados os inúmeros conflitos inerentes ao processo de patrimonialização de bens cravados na paisagem urbana e, ao mesmo tempo, os grupos que terão mais condições de territorializar os espaços públicos com suas referências.

Em agosto de 1993 o jornal Folha da Mata, importante semanário da cidade de Viçosa (MG), publicou o seguinte artigo:

\begin{abstract}
Viçosa e seu patrimônio histórico
Como qualquer outra cidade brasileira, Viçosa vem crescendo sempre com a caótica da remoção dos seus prédios de inequívoco valor histórico, arquitetônico e cultural, que participaram por décadas na formação da identidade local, como referências concretas de espaço e tempo. A tão decantada modernidade está trocando seus belos casarões por prédios novos de porte muito maior, com muitas unidades residenciais ou comerciais, e sempre aumentando densidade populacional, o que acarreta vários problemas de infraestrutura urbana. [...] Com isso, a cidade vai ficando com uma "cara" insossa à medida em que vai desfigurando continuamente a sua identidade [...] Um programa de preservação não pode ser apenas questão de uma eventual prioridade por um ou outro esquema político, ou de uma consciência individual por parte dos proprietários de bens particulares, sob o risco de convivermos com uma grande ameaça de chegarmos a uma triste “amnésia social”. (SECRETARIA MUNICIPAL DE CULTURA, 1993, p. 7 - grifos nossos).
\end{abstract}

José Reginaldo Santos considera mutualística a relação entre o discurso da perda e a criação de relíquias a serem preservadas. Segundo o autor, esse seria um processo de cismogênese, que, segundo o discurso propagado, ocorre entre a identidade e a memória que estão se perdendo e a necessidade de preservar ícones que as manterão preservadas. Esse discurso que propaga o esmaecimento da memória e da identidade e luta o "bom combate" pela sua preservação, é denominado pelo autor como "retórica da perda" (GONÇALVES, 1996, p. 23).

Em Viçosa, entre a década de 1980 e a primeira metade dos anos 90, observa-se a divulgação de um discurso identitário local e a preocupação de políticos, intelectuais e

\footnotetext{
${ }^{1}$ SECRETARIA MUNICIPAL DE CUlTURA. Viçosa e seu patrimônio histórico. Folha da Mata, Viçosa, n. 1 (280), 28 ago. 1993. p. 7.
} 
empresários com o desenvolvimento do Turismo. A partir de 1998, o município contaria com os trabalhos do Conselho Municipal do Patrimônio, principal órgão que estaria à frente da elaboração de políticas públicas de preservação patrimonial em Viçosa. Seja pela "defesa da memória e da identidade", seja pela melhoria da qualidade de vida ou ainda, para melhorar a infraestrutura urbana, o que se verá, é uma preocupação em desenvolver políticas públicas que viabilizassem tais objetivos. Nesse ínterim é que foram criados o Plano Diretor de Viçosa (PDV), o Conselho Municipal de Cultura, Patrimônio Cultural e Ambiental de Viçosa (CMCPCAV), o Museu Casa Arthur Bernardes (MCAB) e os decretos de tombamentos municipais.

A análise dos discursos identitários formulados por determinados grupos sociais em Viçosa e da legislação patrimonial do município, permite considerar que as preocupações em preservar a memória e estabelecer os elementos de uma identidade local, o desenvolvimento do setor do Turismo e a defesa do patrimônio históricocultural e arquitetônico de Viçosa, estiveram intimamente ligados. Tal debate, evidentemente, não perpassou toda a comunidade de Viçosa, mas concentrou-se, especialmente, entre grupos ligados à Universidade Federal de Viçosa (UFV), mais especificamente ao Departamento de Arquitetura e Urbanismo (DAU/UFV) e à Prefeitura Municipal de Viçosa (PMV).

Uma questão relevante para a análise das ações em defesa do patrimônio de Viçosa é que no momento em que eles se tornaram mais enfáticos, seus defensores buscaram nos discursos oficializados como a "história de Viçosa", o embasamento para falarem de "perda da memória, da identidade ou das tradições". Para tanto, utilizariam obras de memorialistas locais, como, por exemplo, a professora Maria do Carmo Tafuri Paniago, dando a elas um "lugar de autoridade" que não apenas seria difundido como "a história de Viçosa" como também - pelo peso dado à história e à memória - embasaria os debates e as políticas públicas patrimonialistas, com argumentos tidos como inquestionáveis.

Deve-se considerar, entretanto, que talvez esse não tenha sido o objetivo da professora Paniago ao escrever tantos trabalhos sobre Viçosa e seus "grandes vultos", "importantes acontecimentos históricos" e "mudanças culturais". No entanto, seu discurso foi apropriado por um determinado grupo social e passou a ser percolado a uma identidade local difundida por esse grupo. Dessa forma, os defensores do patrimônio (e pretensos defensores da memória e da identidade vistas como intrínsecas a ele), passaram a justificar suas ações patrimoniais através das obras de Paniago 
tomadas como "verdade absoluta" sobre Viçosa. Esse grupo social, cujas referências utilizadas se tornaram oficiais, foi responsável por consideráveis mudanças na paisagem urbana de Viçosa, ao longo das décadas de 1990 e 2010, por meio da seleção entre o que seria preservado e o que seria demolido na cidade.

A evolução da legislação patrimonial de Viçosa demonstra como a questão vai ganhando peso ao longo das décadas de 70, 80 e 90. A partir de então, os discursos preservacionistas, a memória coletiva sobre o desenvolvimento desordenado da cidade, tornavam oficial, o "discurso da perda". A criação da Lei "Robin Hood", em 1995, pelo Estado de Minas Gerais, concedendo incentivos financeiros aos municípios que empenhassem esforços na preservação de seu patrimônio histórico-cultural deve ser considerada um importante elemento propulsor daquele desenvolvimento de políticas patrimoniais no município de Viçosa. Entretanto, responsabilizar unicamente a Lei "Robin Hood" seria negligenciar todos os discursos voltados à preservação da memória e da identidade local, difundidos em Viçosa desde a década de 1980. Deve-se considerar ainda, toda a preocupação do Poder Público e de empresários locais em desenvolver a indústria do turismo como alternativa de ganhos econômicos para o município.

A existência de um curso de graduação em Arquitetura e Urbanismo na UFV, criado em 1992, também é um fator que deve ser considerado nesse contexto. A avaliação do Governo Estadual para fins de repasse do ICMS Cultural é feita segundo critérios do Instituto Estadual do Patrimônio Histórico e Artístico de MG (IEPHA). Há uma predominância de arquitetos e de critérios arquitetônicos para avaliar os bens tombados e as políticas de preservação. A existência de profissionais dessa área, no CMCPCAV (também) teve influência direta sobre as políticas patrimoniais em Viçosa.

O ano de 1999 foi um dos mais importantes para o CMCPCAV, pois, sete dos dezessete bens tombados até hoje pelo município, tiveram seus Decretos publicados somente naquele ano. Nesse processo, pode-se destacar a atuação marcante dos conselheiros arquitetos que elaboraram, apresentaram para apreciação do Conselho e tiveram "unanimemente" aprovados, os dossiês de tombamentos de todos os bens. Foram tombados de uma só vez, o Colégio Viçosa, a Casa Arthur Bernardes (já tombada pelo Decreto Estadual no 29399 de 21 de abril de 1989), o edifício da Escola Municipal Edmundo Lins, a Balaustrada, localizada à Avenida Bueno Brandão e a Estação Ferroviária, todos no Centro de Viçosa. Também foram tombados o Parque Tecnológico de Viçosa - CENTEV (Antigo Patronato Agrícola), localizado na Avenida Oraída Mendes de Castro s/n ${ }^{\circ}$, Silvestre e o Livro de Atas da Câmara de Vereadores do 
município de Viçosa, do período entre 1903 e 1909 - quando foi assinada pelo então Presidente da Câmara Arthur da Silva Bernardes. Foram registrados em Ata de reunião do Conselho do Patrimônio, os elogios feitos pelos técnicos do IEPHA aos dossiês enviados por Viçosa, todos eles elaborados por arquitetos, professores do DAU/UFV e conselheiros do patrimônio de Viçosa.

Em meio a esse trabalho de preservação do CMCPCAV, o tombamento de um bem levantaria uma polêmica. Foi apresentada ação de impugnação à proposta de tombamento do Colégio de Viçosa, por um de seus acionistas. Esse impasse inauguraria uma nova etapa nos trabalhos do Conselho. Estava aberta a temporada de conflitos entre o interesse de preservar do CMCPCAV e os interesses econômicos dos proprietários dos bens inventariados ou tombados e dos representantes do setor imobiliário de Viçosa, uma das atividades mais lucrativas da cidade. É evidente que entre todos os bens listados até agora como sugestões dos conselheiros para possíveis tombamentos, o único que gerou esse tipo de problema foi o Colégio de Viçosa e não por acaso. A primeira grande leva de tombamentos em Viçosa abarcou principalmente bens imóveis públicos, pertencentes ao município ou à UFV. Entre eles, o único bem parcialmente privado foi o Colégio de Viçosa e, portanto, o único que apresentou uma dificuldade maior aos conselheiros.

Em 2001 foi aprovado pela UFV o tombamento do Edifício Arthur Bernardes uma das primeiras edificações que deram início à Escola Superior de Agricultura e Veterinária (ESAV), na década de 1920. Também naquele ano, foi tombada a Estação Ferroviária de Silvestre. Em 2004, as casas n¹19 e nº129 da Rua Gomes Barbosa, além da Escola Municipal Coronel Antônio da Silva Bernardes (CASB), localizada à Rua Benjamin Araújo, $\mathrm{n}^{\mathrm{o}}$ 71, todas no Centro da cidade foram tombadas. A fachada do Primeiro Hospital de Viçosa e a Capela dos Passos, ambas localizadas no centro, também passaram por esse processo em 2004. No ano de 2006 foi tombada parte da volumetria da Casa Cora Bolívar, situada à Avenida Bueno Brandão. Em 2008 o tombamento da Ala Antiga do Hospital São Sebastião, localizada à Rua Tenente Kümmel, também no Centro, completaria o conjunto de bens preservados por Lei do município de Viçosa. Também foi tombada a vespa do professor José Lopes de Carvalho, embora não se tenham informações nem sobre o bem, nem sobre os documentos acerca de seu tombamento.

A partir dos tombamentos de tais construções, a paisagem urbana de Viçosa sofria uma considerável alteração: edifícios antigos, possivelmente pouco perceptíveis 
naquele cenário tão familiar e cotidiano, agora se tornavam alvos de atenção. Eles se destacavam pelas obras de reforma ou restauro, pelos eventos realizados ou instituições neles instaladas, pelos debates que suscitariam ainda por um bom tempo. Esperava-se que eles se destacassem na paisagem de Viçosa como os ícones da memória e da identidade daquela comunidade.

Ressalta-se a participação de arquitetos e estudantes de Arquitetura e Urbanismo da UFV em todo o processo, exatamente para enfatizar a influência de suas concepções, de sua formação e de sua atuação prática por meio do Conselho de Patrimônio, modelando a nova paisagem urbana de Viçosa, com seus ícones patrimoniais. Para usar a expressão de Márcia Chuva, assim como ocorreu no SPHAN em nível nacional, também em Viçosa, a existência da UFV e do DAU contribuiu para que o patrimônio tombado da cidade fosse o fruto dos "arquitetos da memória" (CHUVA, 2009). Esses profissionais eram munidos de conhecimentos técnicos específicos e do discurso de autoridade que construíram no âmbito das práticas patrimoniais no Brasil. Além disso, elaboravam documentos que seriam avaliados pelos seus pares no IEPHA, e encontraram um ambiente social e politicamente propício à defesa do patrimônio em Viçosa. Os arquitetos receberam e assumiram a missão de elaborar a "paisagem patrimonial de Viçosa”.

Chama a atenção, por exemplo, o fato de que já nas primeiras reuniões do CMCPCAV, as Atas produzidas não registram discussões dos conselheiros para definir quais seriam os bens tombados. O que se vê são menções de bens, seguidas de aprovações unânimes o que demonstra a existência, entre aquele grupo, de uma ideia mais ou menos formada a priori, acerca de quais bens seriam patrimônios de Viçosa. A visão bem definida do que poderia ser considerado patrimônio, restringia essa possibilidade apenas a determinados bens da cidade.

Também é importante ressaltar o papel dos órgãos gestores do patrimônio como o IPHAN e o IEPHA, e das políticas públicas patrimoniais a níveis estadual e federal naquele processo. Os critérios de pontuação são definidos por esses órgãos e legislações. No caso de Minas Gerais, onde há o envolvimento direto de recursos financeiros através da Lei "Robin Hood", existe um grande empenho da parte dos municípios em selecionar bens e elaborar documentos a seu respeito, que atendam às demandas dos avaliadores. É evidente que nesse processo, contam muito as ações políticas e os interesses econômicos, além dos valores e objetivos sociais do patrimônio histórico-cultural. Esse é mais um ponto que embasa o argumento de que o patrimônio é 
elaborado a partir de um processo difuso, composto de muitas intencionalidades e por atores que mobilizam papeis sociais distintos. O resultado desse movimento é a paisagem urbana territorializada pelos discursos que, em cada contexto, foram vitoriosos por alguma razão.

\section{A utilização do recurso da transferência do potencial construtivo (TPC) e a preservação do patrimônio histórico-cultural no município de Viçosa-MG}

Outro ponto que merece ser destacado dentre as discussões do CMCPCAV ao longo da década de 2000 refere-se a um instrumento previsto no Plano Diretor de Viçosa (PDV) para auxiliar na preservação dos "casarões antigos" da cidade. Trata-se do recurso jurídico denominado "Transferência do Potencial Construtivo" (TPC), ou seja, a possibilidade de que a construtora transferisse para um endereço de sua escolha, o potencial construtivo referente a uma propriedade sua, considerada de interesse público, por valor patrimonial. Após os tombamentos de edificações públicas, o CMCPCAV lançaria mão desse recurso para tentar preservar imóveis considerados de valor histórico e/ou arquitetônico de Viçosa e que pertencessem a particulares ou a empresas privadas. Em Viçosa, os arquitetos que estiveram à frente da elaboração do PD também participavam do Conselho do Patrimônio, os dois trabalhos foram pensados conjuntamente e como instrumentos complementares, no intuito de proteger $\mathrm{o}$ patrimônio do município.

As Atas das reuniões realizadas ao longo da década de 2000 trazem inúmeros registros de pedidos de proprietários aos membros do Conselho para que liberassem a demolição de seus imóveis, já inventariados pelo município. Ao mesmo tempo, nota-se um considerável número de representantes de construtoras e incorporadoras da cidade, dirigindo-se ao Conselho para usufruir o direito de TPC. Em alguns casos, as indicações de imóveis para tombamento, vinham desses mesmos representantes, demonstrando seu grande interesse, não necessariamente pela preservação patrimonial, mas, possivelmente, pelas vantagens econômicas que a TPC proporcionava. Por um lado, a utilização daquele recurso tornou-se uma boa moeda de troca do Conselho Municipal do Patrimônio, frente às pressões do setor imobiliário e da construção civil. No entanto, abria um precedente que, na prática, tornava inoperante o PD que havia sido elaborado para o município. 
Dois casos do uso de TPC se tornaram emblemáticos em Viçosa: o da casa que pertenceu à senhora Cora Bolívar e o casarão onde havia funcionado o primeiro hospital de Viçosa, ambos localizados à Avenida Bueno Brandão (Balaústre), no Centro da cidade. Como resultados da discussão no CMCPCAV, houve a criação de uma legislação municipal voltada para a proteção do patrimônio histórico-arquitetônico da cidade, com a utilização da TPC e a efetivação dos tombamentos de fachadas ou de casarões completos, transferindo-se seu potencial construtivo para outros logradouros.

A partir dessa determinação, foi posta em prática a primeira experiência de Viçosa com o tombamento de fachada por meio do recurso à TPC. A Fachada da Casa Sede do Primeiro Hospital de Viçosa.

\section{Figura 1 - Fachada da Casa Sede do Primeiro Hospital de Viçosa, MG. Bem tombado como patrimônio da cidade, desde 2004}

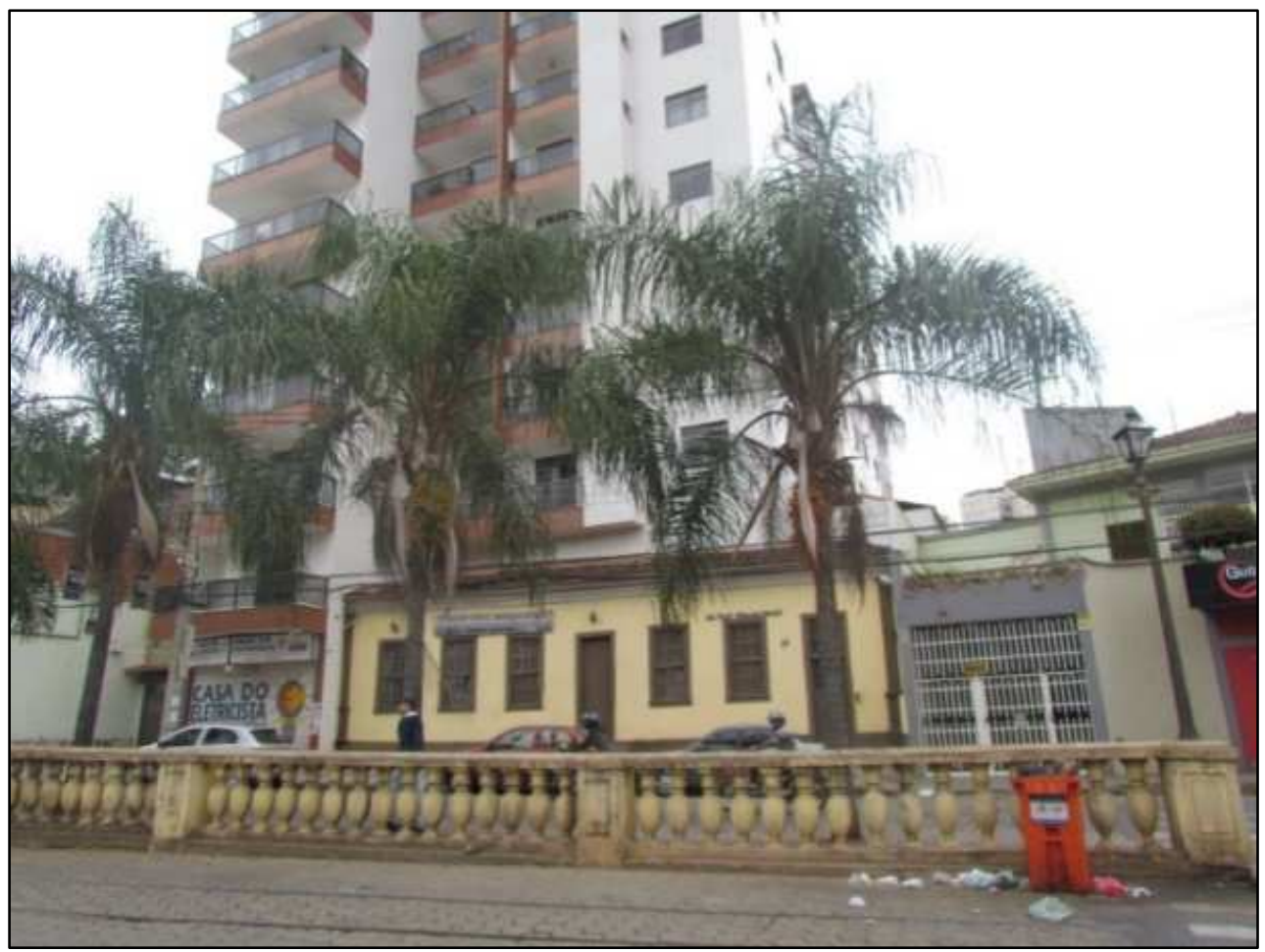

Fonte: Acervo pessoal, 05/07/2015.

Observa-se, na imagem, que apenas a fachada da antiga casa foi tombada, liberando o restante da volumetria do terreno para a construção de um novo edifício, logo atrás do bem tombado. Nesse caso, nada além da "aparência antiga" do casarão poderia ser aproveitado pela comunidade viçosense. Por se tratar apenas de uma 
preservação visual, é difícil imaginar qualquer possibilidade de relação que os moradores possam estabelecer com essa fachada ou qualquer sentido que a ela possa ser atribuído, no novo contexto da cidade. Assim, uma análise dos resultados obtidos com a aplicação da TPC para a preservação de fachadas antigas em Viçosa, deveria abarcar, sobretudo, os ganhos - ou a falta deles - para a sociedade.

Ao longo do ano de 2002, foram intensas as discussões entre o CMCPCAV e os familiares de Dona Cora Bolívar, herdeiros da sua casa. Entretanto, esse debate se estenderia até 2006, quando foi formalizado o pedido de tombamento, a pedido de construtoras e incorporadoras locais. O tombamento da fachada e de parte da volumetria da Casa Cora Bolívar, situada à Avenida Bueno Brandão, $\mathrm{n}^{\circ} 254$, foi oficializado por meio do Decreto $n^{\circ}$ 4057/06 de 30 de agosto de 2006. Assim, como resultado dos trabalhos do CMCPCAV e com o apoio dos Poderes Legislativo e Executivo Municipais, ficava concluído mais um tombamento de fachada e, surgia mais uma materialização de tais esforços, na paisagem urbana de Viçosa.

Figura 2 - Residencial Cora Bolívar.

Detalhe da volumetria preservada da antiga casa de Dona Cora Bolívar

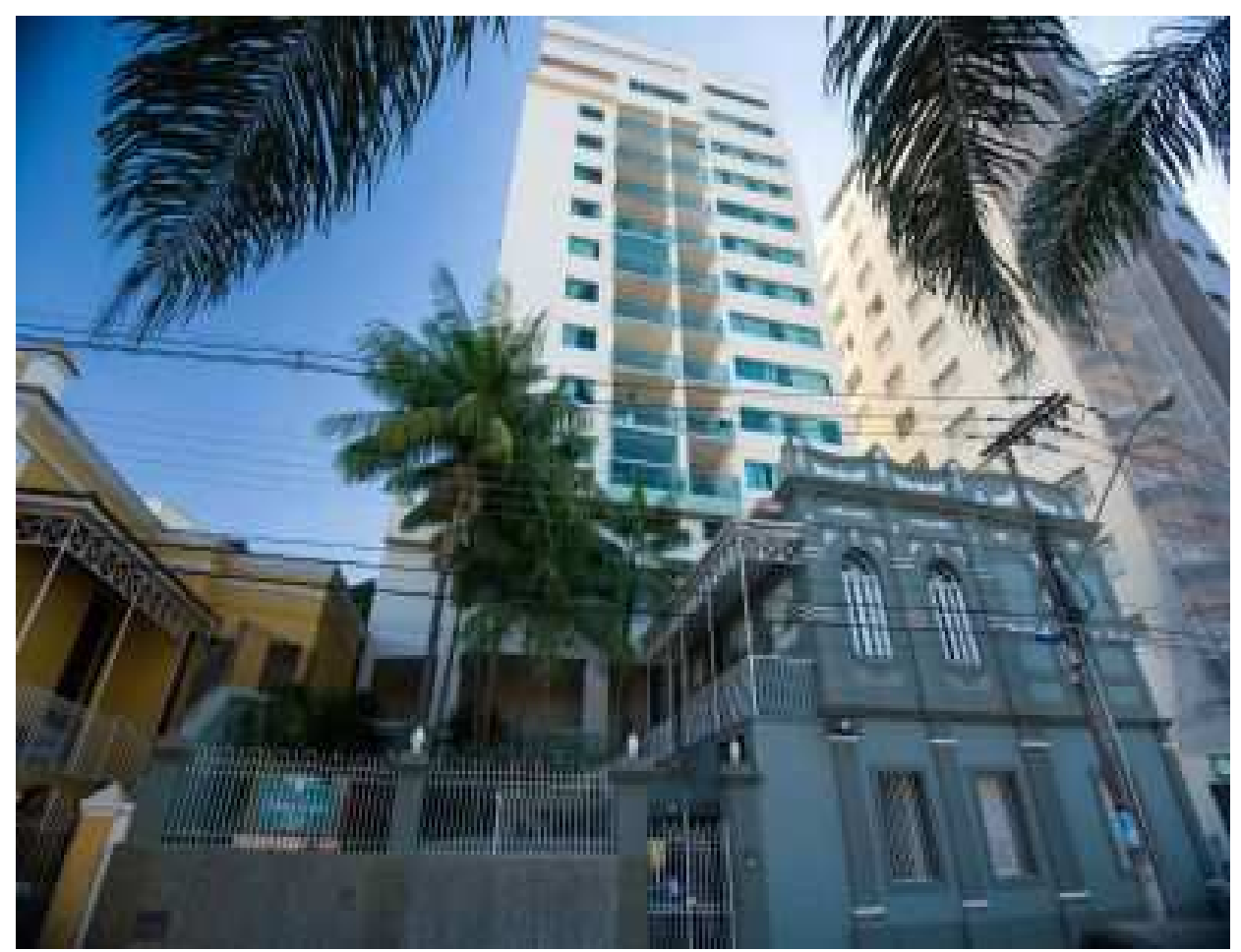

Fonte: Acervo A3 Empreendimentos Imobiliários. 
Nesse exemplo, observa-se que além da fachada da antiga residência de "Dona Cora Bolívar", houve a preservação de parte de sua volumetria. Atualmente, essa parte da antiga casa é utilizada como hall de entrada do "Residencial Cora", considerado um logradouro de luxo, localizado no Centro de Viçosa. Nesse caso, em que uma parte do antigo imóvel foi preservada e tombada como patrimônio da cidade, valeria também uma reflexão sobre a acessibilidade a esse patrimônio "público". Se considerarmos a possibilidade de que muitos grupos sociais de Viçosa percebam a fachada da casa de "Dona Cora" como uma referência e que a memória à qual ela está ligada seja importante para muitos de seus moradores, estaremos diante de uma necessária reflexão. Seria interessante pensar sobre a maneira pela qual a relação entre o bem tombado e a sociedade poderia se efetivar, tendo em vista que, para além da questão visual, esse bem nunca deixou de ser estritamente privado.

\section{Considerações finais}

No Brasil, as políticas de preservação de bens históricos e culturais foram elaboradas, desde os anos 30 do século passado, pelo Serviço de Patrimônio Histórico e Artístico Nacional (SPHAN). Fruto de um projeto de Estado Nacional que, por um lado, planejava o futuro sonhando com projetos de modernização e, por outro, se ancorava no passado de uma identidade nacional idealizada, o SPHAN se esmerou em políticas públicas que garantissem a memória nacional e o patrimônio histórico. Tendo por base a historiografia oficial, bem como, sólidos valores estéticos construídos na aurora da modernidade, o patrimônio histórico e cultural brasileiro foi sendo construído pelo SPHAN. Tais políticas públicas de preservação e conservação se desdobrariam pelos institutos estaduais e por uma miríade de órgãos municipais criados para essa finalidade. Não há, portanto, como negligenciar o importante papel dos órgãos estaduais e municipais na preservação, reconstrução ou ressignificação das variadas paisagens urbanas das cidades espalhadas por todo o país.

Entretanto, as três últimas décadas do século passado foram o berço de profundas transformações no Brasil e no resto do planeta. No âmbito interno, o SPHAN se transformaria em IPHAN, deixaria de lado o binômio nacional e popular e adotaria novos critérios para enquadrar o patrimônio nacional. As noções de patrimônio imaterial, que incluiria a multiplicidade de formações culturais que se estendiam por todo o território nacional são o resultado dessas modificações. Curiosamente, o período 
inaugurado a partir da década de 1970, se notabilizaria também pela proposta da Conferência Geral da Organização das Nações Unidas para a Educação, Ciência e Cultura, no sentido de preservar o patrimônio material e imaterial em todo o planeta.

Além disso, o período foi marcado por profundas transformações no tempo e no espaço. As alterações na base produtiva influiriam diretamente sobre as relações interpessoais. A fluidez das relações e a revolução nas informações provocariam uma sensação de instabilidade e ansiedade. $\mathrm{O}$ acelerado processo de globalização nutria o fortalecimento de novas tramas discursivas entre os grupos sociais. Esses discursos fundamentariam distintas identidades e construíam memórias coletivas ancoradas às "originalidades" do "passado". Uma espécie de retórica vazia do "monumentalismo" historicista do século XIX (CIVALE, 2015, p. 142). Por essa razão, na contemporaneidade, não apenas o passado, através dos vestígios que chegaram ao presente, passaria a ser investidos da autoridade de "verdade histórica", mas também o espaço urbano seria alvo de encarniçadas disputas envolvendo o poder público, o capital privado, e inúmeros grupos sociais.

Le Goff se ancora na prosa de Paul Valéry para tratar da objetividade e da imparcialidade necessárias ao trabalho do pesquisador: "A história é o produto mais perigoso que a química do intelecto elaborou [...]. A história justifica o que se quiser. Não ensina rigorosamente nada, pois tudo contém e de tudo dá exemplos." (LE GOFF, 1996, p. 32). Tal afirmação facilita a compreensão não apenas do uso do discurso histórico na defesa da memória, da identidade, das tradições e da originalidade, mas, sobretudo, do peso desse discurso histórico para chancelar não importa quais interesses.

A observação e interpretação da atual paisagem urbana de Viçosa devem considerar que, em certa medida, ela é o fruto da ação deliberada de certos grupos sociais, no sentido de privilegiar determinadas referências nos espaços públicos da cidade. Essa paisagem é marcada pela ação do CMCPCAV nas duas últimas décadas, arbitrando entre demolições e tombamentos. Observa-se também a grande influência do IEPHA, definindo uma matriz de seleção e proteção aos bens de valor histórico, cultural e ou arquitetônico dos municípios do Estado de Minas Gerais, devido ao atrativo do recurso financeiro por meio do ICMS Cultural. Também devem ser considerados os interesses políticos e econômicos que perpassam a questão do patrimônio. Eles revelam que a patrimonialização não é apenas fruto de demandas sociais pela valorização da cultura, das tradições, mas também é fruto das negociações frente ao direito da propriedade privada e aos interesses imobiliários e da construção civil. 
Apesar da existência de outros conselheiros, representantes de órgãos educacionais e entidades culturais da cidade, percebe-se a grande influência nos trabalhos do Conselho Municipal do Patrimônio por parte dos arquitetos que dele participaram. Nota-se ainda, que as referências bibliográficas acerca da "história de Viçosa" se reproduzem nos documentos produzidos por aqueles arquitetos. São trabalhos de cunho memorialista, tomados como história única e verdadeira da cidade. Estes foram utilizados para embasar o patrimônio, relacionando-os aos "grandes nomes e acontecimentos" enfatizados pela memória oficial de Viçosa.

Procuramos, portanto, colocar em evidência as relações entre o discurso identitário local e as memórias que, a partir dele, foram selecionadas e tornadas oficiais através de políticas públicas patrimoniais. Enfatizamos a importância de analisar as consequências de tais processos para os diferentes grupos sociais que convivem no espaço da cidade. A preservação do patrimônio histórico-cultural de uma cidade está relacionada à modelagem de sua paisagem urbana, na qual serão "iluminadas" determinadas memórias. Por outro lado, essa mesma paisagem urbana, denuncia, pela ausência, os diversos grupos sociais cujas memórias são "obscurecidas" ou silenciadas e cujas referências não recebem a chancela do Poder Público.

O que propusemos com esta análise é explicitar o jogo de "luzes e sombras" (CIVALE, 2015) que constitui o processo patrimonialista e, a partir dessa reflexão, propor discussões acerca do acesso que alguns grupos sociais têm e outros não, aos espaços públicos da cidade.

Flanar por Viçosa, hoje, é ter a oportunidade de ler na paisagem urbana um texto, em parte, "escrito" pelo CMCPCAV. A avaliação desses atos para a cidade exigirá novas pesquisas. Nosso objetivo foi demonstrar como se deu o processo, quem foram os protagonistas, quais as questões mais relevantes no percurso, bem como, as soluções apresentadas. Os resultados imediatos podem ser vistos, principalmente, na paisagem da região central da cidade. 


\section{REFERÊNCIAS}

BAUDELAIRE, Charles. As Flores do Mal. Trad. Ivan Junqueira. Rio de Janeiro: Nova Fronteira, 2012. Disponível em: <file:///E:/As\%20Flores\%20do\%20Mal\%20\%20Charles\%20Baudelaire.pdf>. Acesso em: 25 out. 2016.

BAUMAN, Zygmunt. Identidade. Rio de Janeiro: Jorge Zahar Editor, 2005.

BESSE, Jean-Marc. O Gosto do Mundo: exercícios de paisagem. Tradução: Annie Cambe, Rio de Janeiro: Eduerj, 2014.

BOURDIEU, Pierre. O poder simbólico. Lisboa: Difel, 1989.

CARVALHO, Aline Werneck Barbosa de. A transferência do potencial construtivo como mecanismo de preservação do patrimônio cultural: Uma experiência concreta. Minha Cidade. Viçosa MG Brasil ano 04, fev. 2004. Disponível em: <http://www.vitruvius.com.br/revistas/read/minhacidade/04.043/2020>. Acesso em: 28 dez. 2015.

CASTELLS, Manuel. O poder da identidade. Trad. Klauss Brandini Gerhardt. $2^{\mathrm{a}}$ ed. São Paulo: Paz e Terra, 2000.

CERTEAU, Michel de. Andando na cidade. Revista do Patrimônio Histórico e Artístico Nacional (IPHAN), Rio de Janeiro, n. 23, p. 21-31, 1994.

CHOAY, Françoise. A alegoria do Patrimônio. São Paulo: Estação Liberdade/Editora UNESP, 2001.

CHUVA, Márcia Regina Romeiro. Os Arquitetos da Memória. Rio de Janeiro: Editora UFRJ, 2009.

CIVALE, Leonardo. Sobre Luzes e Sombras: A revitalização da Praça XV de Novembro no centro histórico da cidade do Rio de Janeiro e o papel da paisagem urbana como patrimônio cultural (1982-2012). Cadernos de Geografia, Belo Horizonte, v. 25, n. 44, p. 134-148, 2015.

COSGROVE, Denis. A geografia está em todo lugar: cultura e simbolismo na geografia humana. In: CORREAA, Roberto Lobato; ZENY, Rosendahl. Paisagem, tempo e cultura. Rio de Janeiro: Eduerj, 2004, $2^{\mathrm{a}}$ ed.

SECRETARIA MUNICIPAL DE CULTURA. Viçosa e seu patrimônio histórico. Folha da Mata. Viçosa - MG. No 1.280 de 28/08/1993. P.7. O acervo encontra-se disponível para consulta na redação do jornal Folha da Mata, em Viçosa-MG e está organizado apenas de acordo com as datas dos jornais.

GONÇALVES, José Reginaldo Santos. A retórica da perda: os discursos do patrimônio cultural no Brasil. Rio de Janeiro: UFRJ; IPHAN, 1996.

GUMBRECHT, Hans Ulrich. Nosso amplo presente: o tempo e a cultura contemporânea. Trad. Ana Isabel Soares. 1ª Ed. São Paulo: Editora Unesp, 2015. 
HALL, Stuart. A identidade Cultural na Pós-Modernidade. Rio de Janeiro: DP\&A, 2004.

HARVEY, David. A condição pós-moderna. Tradução: Ubirajara Sobral e Maria Stela Gonçalves. São Paulo: Edições Loyola, 1992.

LE GOFF. J. História e Memória. Campinas: Editora UNICAMP, 1996.

NORA, Pierre. Entre memória e História. A problemática dos lugares. Projeto História, São Paulo, n. 10, p.7-28, dez. 1993.

PANIAGO, Maria do Carmo Tafuri. Viçosa: mudanças Socioculturais. Evolução Histórica e tendências. Viçosa: Editora UFV, 1990.

PANIAGO, Maria do Carmo Tafuri. Viçosa: tradições e folclore. $2^{a}$ ed. Viçosa: Editora UFV, 1983.

POLLAK, Michael. Memória, esquecimento, silêncio. Estudos Históricos, Rio de Janeiro, v. 2, n. 3, p.3-15, 1989.

POULOT, Dominique. Uma história do patrimônio no Ocidente. São Paulo: Estação Liberdade, 2009.

RIBEIRO FILHO, Geraldo Browne. A formação do espaço construído: cidade e legislação urbanística em Viçosa, MG. 1997. 244 f. Dissertação (Mestrado em Urbanismo) - Faculdade de Arquitetura e Urbanismo, Universidade Federal do Rio de Janeiro, Rio de Janeiro 1997.

SCHAMA, Simon. Paisagem e Memória. Trad. De Hildegard Feist. São Paulo: Companhia das Letras, 2009.

SECRETARIA MUNICIPAL DE CULTURA. Viçosa e seu patrimônio histórico. Folha da Mata, Viçosa, n. 1 (280), 28 ago. 1993. p. 7.

SENNET, Richard. A cultura do novo capitalismo. São Paulo/Rio de Janeiro: Editora Record, 2006.

STEPHAN, Ítalo Itamar Caixeiro; RIBEIRO FILHO, Geraldo Browne. Avanços e limites na implantação de um sistema de planejamento em Viçosa - MG. In: Anais do V Congresso de Ciências Humanas, Letras e Artes. 28 a 31 de agosto de 2001, Universidade Federal de Ouro Preto: Ouro Preto, 2001. Disponível em: <http://www.ichs.ufop.br/conifes/anais/PES/pes0303.htm>. Acesso em: 04 jun. 2015. 